\title{
H/D Exchange Using Hot Heavy Water
}

\author{
Seijiro Matsubara ${ }^{a}$, Kenichi Ishibashia, Gone Yi Thaw Maung ${ }^{b}$, Yuudai Morotaa, Tomomi Umemuraa, \\ and Yumi Kato ${ }^{a}$
}

This paper is dedicated to the memory of Professor Dr. Manfred Schlosser.

\begin{abstract}
Metal-catalyzed H/D exchange in hydrothermal deuterium oxide, performed in an autoclave using external heating or in a sealed glass tube under microwave irradiation, was shown to be an efficient method for preparing various deuterium-labeled compounds. Phosphonium salts for the Wittig reaction were deuterated at the $\alpha$-position in the presence of MS 4A under microwave irradiation; primary alcohols and primary/secondary amines were deuterated at the $\alpha$-position in the presence of ruthenium catalyst under microwave irradiation; metal-catalyzed direct $\mathrm{C}-\mathrm{H}$ functionalizations on $\mathrm{sp}^{3}$ and $\mathrm{sp}^{2}$ carbon gave the corresponding fully deuterated products under hydrothermal conditions. These methods gave various deuterium-labelled compounds efficiently using $\mathrm{D}_{2} \mathrm{O}$ as a $\mathrm{D}$-atom source.
\end{abstract}

Keywords: H/D exchange $\cdot$ Hydrothermal $\cdot$ Microwaves $\cdot$ Palladium $\cdot$ Platinum $\cdot$ Ruthenium
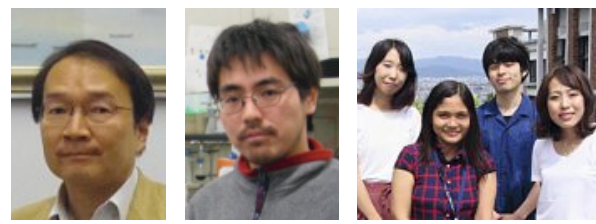

Seijiro Matsubara was educated in chemistry at Kyoto University, completing his PhD in 1986 with Professors Hitosi Nozaki and Kiitiro Utimoto, and at the Université de Lausanne (1984-1985) where he was a $\mathrm{PhD}$ course student with Prof. Manfred Schlosser. He was appointed as an Assistant Professor at Kyoto University in 1986. After postdoctoral research with Prof. Barry M. Trost at Stanford University in 1988-1989, he became an Associate Professor at Kyoto University in 1995. In 2006, he became a Full Professor at Kyoto University. Kenichi Ishibashi obtained MEng degree in 2007, and joined pharmaceutical company, Shionogi Co., LTD, as a chemist, and is $\mathrm{PhD}$ candidate at Kyoto University (2015-). From right: Yumi Kato obtained a BEng degree at Kyoto University in 2017, and Yuudai Morota

\footnotetext{
${ }^{\star}$ Correspondence: Prof. S. Matsubara ${ }^{a}$

E-mail: matsubara.seijiro.2e@kyoto-u.ac.jp

aDepartment of Material Chemistry

Graduate School of Engineering

Kyoto University

Kyotodaigaku-Katsura, Nishikyo, Kyoto 615-8510, Japan

'The Amgen Scholar (http://amgenscholars.com/university/kyoto-university) from Department of Chemistry, University of Mandalay

University Drive, 73rd Street, Mandalay, Myanmar
}

obtained his in 2018. At present, both of them are graduate course students at Kyoto University. Gone Yi Thaw Maung is the Amgen Scholar in 2018 from Department of Chemistry, University of Mandalay. Tomomi Umemura is an undergraduate course student of Kyoto University.

\section{Introduction}

The first isotopic compound encountered in chemistry textbooks is heavy water. This mysterious substance consists of deuterium $\left({ }^{2} \mathrm{H}\right)$ and ordinary oxygen $\left({ }^{16} \mathrm{O}\right)$. The differences in the physical and chemical properties between heavy water and ordinary water are well known. Fish and plants fare poorly when given heavy water. It is also toxic to humans. By contrast, organic compounds in which a hydrogen atom is replaced with a deuterium atom at a specific position are synthesized under the premise that the physical properties are not significantly changed. [1] The typical aim of such studies is to investigate the reaction mechanisms in the presence of isotope effects and to confirm the mechanism of a biosynthetic pathway. ${ }^{[2]}$ In recent years, however, the relatively large strength of the $\mathrm{C}-\mathrm{D}$ bond compared to the $\mathrm{C}-\mathrm{H}$ bond has been employed to alter the properties of organic molecules and synthetic reaction pathways. For example, H-atoms may be replaced with $\mathrm{D}$-atoms to prevent undesired deprotonation reactions during natural product synthesis, and even to retard $\mathrm{H}$-abstraction in organometallic species. ${ }^{[3]}$ D-labeled drugs that inhibit metabolism have also been developed. ${ }^{[4]}$ Fully deuterated organic molecules are known to be optical materials ${ }^{[5]}$ and have attracted significant attention recently for their use in the dynamic nuclear polarization (DNP) method. [6]

Polydeuteration may be achieved using $\mathrm{D}_{2} \mathrm{O}$ or $\mathrm{ROD}$ as the $\mathrm{D}^{+}$source under acidic or basic conditions. ${ }^{[1 \mathrm{c}, \mathrm{d}]}$ Treatment of organic compounds in $\mathrm{D}_{2} \mathrm{O}$ or $\mathrm{D}_{2}$ in the presence of a metal catalyst has been used as an efficient deuteration method. Reactions using $\mathrm{D}_{2} \mathrm{O}$ offer a practical H/D exchange approach and are easy to handle in comparison with $\mathrm{D}_{2}$ gas. In these catalytic reactions, a reaction is carried out under equilibrium conditions. Considering that $\mathrm{C}-\mathrm{D}$ bonds are relatively stable compared to $\mathrm{C}-\mathrm{H}$ bonds, polydeuteration is a thermodynamically favored process. The slightly shorter $\mathrm{C}-\mathrm{D}$ bond length probably reduces the molecular volume, so high pressure conditions are also expected to be advantageous. Water becomes a gas at $100{ }^{\circ} \mathrm{C} / 1 \mathrm{~atm}$. It enters a hydrothermal state upon further heating in a closed container at temperatures exceeding $100{ }^{\circ} \mathrm{C}$. With further heating in a closed container, as shown in Fig. 1, water reaches a critical point at $374{ }^{\circ} \mathrm{C}$ and 22 $\mathrm{MPa}$, a supercritical state. Water in this hydrothermal state has specific physical properties: it has a smaller $\varepsilon$ value (27.1) and a smaller $\mathrm{pKw}(11.2)$ at $270{ }^{\circ} \mathrm{C} / 5 \mathrm{MPa}$ compared to the value under ambient conditions $\left(\varepsilon=78.5\right.$, $\mathrm{pKw}=14$ at $25^{\circ} \mathrm{C} / 0.1$ $\mathrm{MPa}){ }^{[7]}$ This means that the hydrothermal state of water has reduced polarity and is slightly acidic. This state can be easily reproduced using an autoclave to achieve a hydrothermal reaction in the laboratory. Similar hydrothermal states may be readily obtained through microwave (MW) irradiation of a closed vessel, although 
differences between the heating methods complicate any comparison. ${ }^{[8]}$ We sought to test the performances of the various $\mathrm{H} / \mathrm{D}$ exchange protocols under these various conditions.

\section{Hydrothermal and Microwave States of $\mathrm{D}_{2} \mathrm{O}$ in the Presence of Molecular Sieves}

Starting in December, 1984, I spent a year as a graduate student at the Institut de Chimie Organique, Université de Lausanne. My supervisor was Prof. Dr. Manfred Schlosser. This is not a place to write about the impressive events during my stay, but I would like to mention his paper about deuteration. In 1964, Prof. Schlosser had published a very nice report about the preparation of deuterium-substituted alkenes using phosphonium salts deuterated at the $\alpha$-position. ${ }^{[9]}$ The salts were prepared by treating phosphonium salt with basic $\mathrm{D}_{2} \mathrm{O}$ to achieve deuteration at the $\alpha$-position. We attempted to treat ethyltriphenylphosphonium iodide (1a) with $\mathrm{D}_{2} \mathrm{O}$ for $2 \mathrm{~h}$ under hydrothermal conditions $\left(250{ }^{\circ} \mathrm{C} / 4 \mathrm{MPa}\right)$ without the use of an additive. The $\alpha$-position in 1a was deuterated only to $39 \% \mathrm{D}$, but the addition of molecular sieves 4A (MS 4A) changed the situation dramatically. ${ }^{[10]}$ We had also found that $\alpha$-deuteration of acetophenone proceeded efficiently in $\mathrm{D}_{2} \mathrm{O}$ under $\mathrm{MW}$ irradiation in the presence of MS 4A, so we tested the deuteration of phosphonium salts in the presence of MS 4A. Microwave irradiation $\left(180{ }^{\circ} \mathrm{C} / 1.2 \mathrm{MPa}\right)$ was applied for $0.5 \mathrm{~h}$ to a mixture of $1 \mathrm{a}$ and $\mathrm{D}_{2} \mathrm{O}$ in the presence of MS 4A to give the $\alpha$-deuterated phosphonium salt 2a. These protocols were applied to various phosphonium salts to demonstrate the generality of the method. Interestingly, MW irradiation induced decomposition of the substrate, depending on the type of phosphonium salt present (Scheme 1). Molecular sieves, a dehydration reagent, are considered to play the role of an acid. ${ }^{[11]}$ Some reports note that they can act as a weak base under MW irradiation. ${ }^{[12]}$ During MW irradiation in $\mathrm{D}_{2} \mathrm{O}$, molecular sieves work not only as a heating core, but also as an appropriate base. Undesired reactions caused by a strong base can be avoided by using molecular sieves as a solid-state mild base.

\section{Ruthenium-catalyzed Reaction of Primary Alcohol in $\mathrm{D}_{2} \mathrm{O}$}

The regioselective oxidation of a primary alcohol in the presence of a secondary alcohol remains a challenging issue. The secondary alcohol is oxidized preferentially, and oxidation proceeds via a relatively stable secondary radical or cation intermediate. ${ }^{[13]}$ On the other hand, during hydrogen transfer-type oxidation via a metal alkoxide, primary alcohols are oxidized faster than secondary alcohols due to the ease of forming metal-alkoxides and incurring $\beta$-elimination. ${ }^{[14]}$ For example, use of $\mathrm{RuCl}_{2}\left(\mathrm{PPh}_{3}\right)_{3}$ for the selective oxidation of a primary alcohol in the presence of a secondary alcohol is a practical approach. We previously reported a $\mathrm{RuCl}_{2}\left(\mathrm{PPh}_{3}\right)_{3}$-catalyzed oxidation reaction of primary alcohols using 3-buten2-one as a hydrogen acceptor.[15] This reaction was performed without the addition of a solvent. During this study, we noticed that the presence of water in the

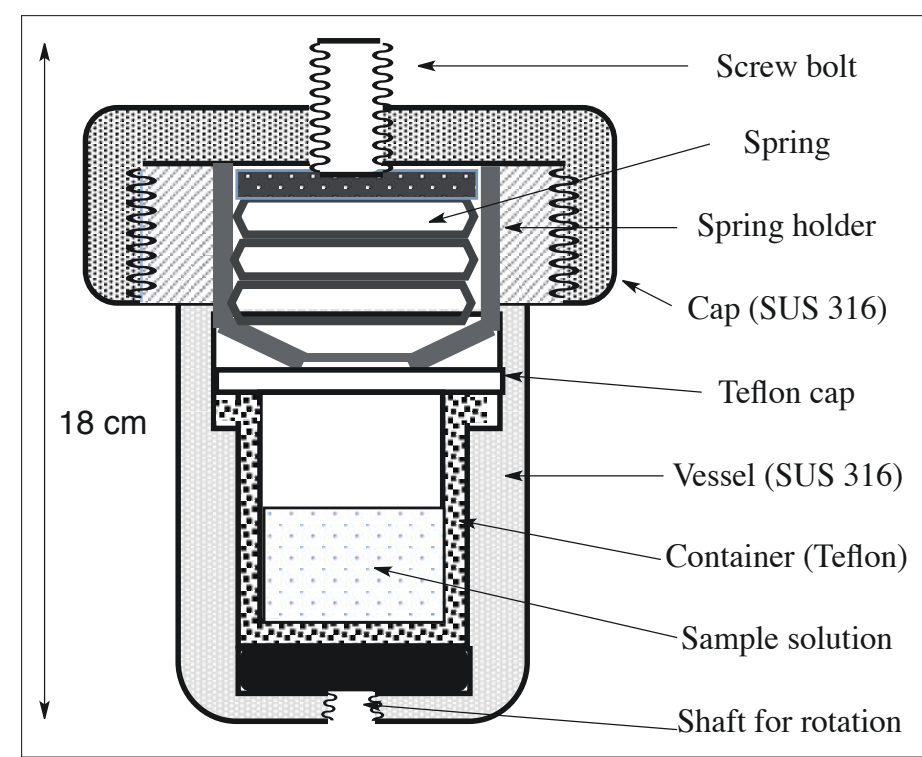

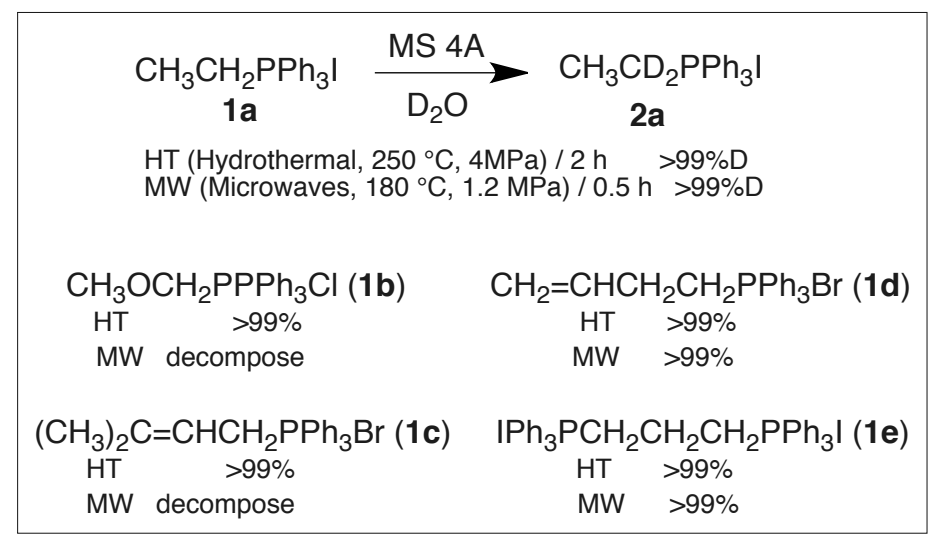

\begin{tabular}{|c|c|}
\hline & $\begin{array}{l}\text { Ligand } \\
\text { Exchange }\end{array}$ \\
\hline \multirow{2}{*}{$\mathrm{RCH}_{2} \mathrm{OH}+\mathrm{RuL}_{n} \mathrm{Cl}$} & $\beta$-Elimination \\
\hline & $\mathrm{RCH}_{2} \mathrm{ORuL}_{n} \rightleftharpoons(\mathrm{RCH}=\mathrm{O}) \mathrm{RuHL}_{n}$ \\
\hline \multirow{2}{*}{$\mathrm{RCHDOD}+\mathrm{RuL}_{n} \mathrm{Cl}$} & $-\mathrm{DCl}$ \\
\hline & $\underset{+\mathrm{DCl}}{\rightleftharpoons} \mathrm{RCHDORuL}_{n} \rightleftharpoons(\mathrm{RCH}=\mathrm{O}) \mathrm{RuDL}_{n}$ \\
\hline
\end{tabular}

reaction mixture resulted in the recovery of the starting alcohol. This negative effect on oxidation indicated that the equilibrium shown in Scheme 2 was inclined toward the alcohol side of the reaction in the presence of water. In the equilibrium, ruthenium hydride was formed by $\beta$-hydride elimination. The formed ruthenium hydride was converted into ruthenium deuteride in $\mathrm{D}_{2} \mathrm{O}$. As a result, the thermodynamically-favored deuterated product accumulated through this equilibrium. ${ }^{[16]}$

In fact, treatment of the primary alcohol $\mathbf{3}$ with a ruthenium catalyst under MW irradiation in a sealed tube gave the corresponding D-labeled alcohol 4 regioselectively (Scheme 3 ). Microwave irradiation of $\mathbf{3 a}$ was replaced with reflux conditions of $\mathrm{D}_{2} \mathrm{O}$ at $0.1 \mathrm{MPa}$ under

Fig. 1. Typical autoclave for use in hydrothermal reactions. ${ }^{[8 c]}$

Scheme 1.

Deuteration of the $\alpha$-positions of phosphonium salts in hot $\mathrm{D}_{2} \mathrm{O}$ in the presence of MS 4A.

Scheme 2.

Ruthenium-mediated equilibrium between a primary alcohol and an aldehyde in the presence of $\mathrm{D}_{2} \mathrm{O}$. 
external heating for $24 \mathrm{~h}$ to obtain the corresponding $\mathbf{4 a}$ with $85 \%$ D contribution. The reaction of the primary alcohols carrying a protected hydroxyl group (3d-3f) was also examined. To prevent deprotection by protonation, milder conditions $\left(100{ }^{\circ} \mathrm{C} / 0.15 \mathrm{MPa}\right)$ under basic conditions (1 M NaOD) were applied to obtain the corresponding D-labeled compounds efficiently (4d-4f). The chiral center at $\beta$-position was not affected (5 to 6 ).

This protocol is applicable to primary and secondary amines (Scheme 4). The reaction was assumed to proceed via an amine-imine/iminium equilibrium in the presence of a ruthenium catalyst. [16]

The intermediate ruthenium hydride could be used to achieve alkene migration via repeated hydrometalation $/ \beta$ - elimination. This alkene migration was attempted in $\mathrm{D}_{2} \mathrm{O}$, and $\mathrm{H}$-atoms were found to be replaced with $\mathrm{D}$-atoms, the footprint of ruthenium atom passage. Treatment of cyclohexene with catalytic amounts of $\mathrm{RuCl}_{2}\left(\mathrm{PPh}_{3}\right)_{3}$ and ethanol under MW irradiation $\left(140{ }^{\circ} \mathrm{C} / 0.34 \mathrm{MPa}, 1 \mathrm{~h}\right)$ provided a $13 \%$ deuterium distribution in the recovered cyclohexene. Ethanol was replaced with sodium dodecylsulfate (SDS) as an additive $(10 \mathrm{~mol} \%)$, and a $97 \%$ deuterium distribution was observed (Scheme 5). [17] Conventional methods involving a metal catalyst and $\mathrm{D}_{2} \mathrm{O}$ under hydrothermal conditions suffer from the formation of benzene via dehydrogenation. The ruthenium hydride-mediated reaction is irreplaceable for preparing fully deuterated cyclohexene via direct H/D exchange of cyclohexene.

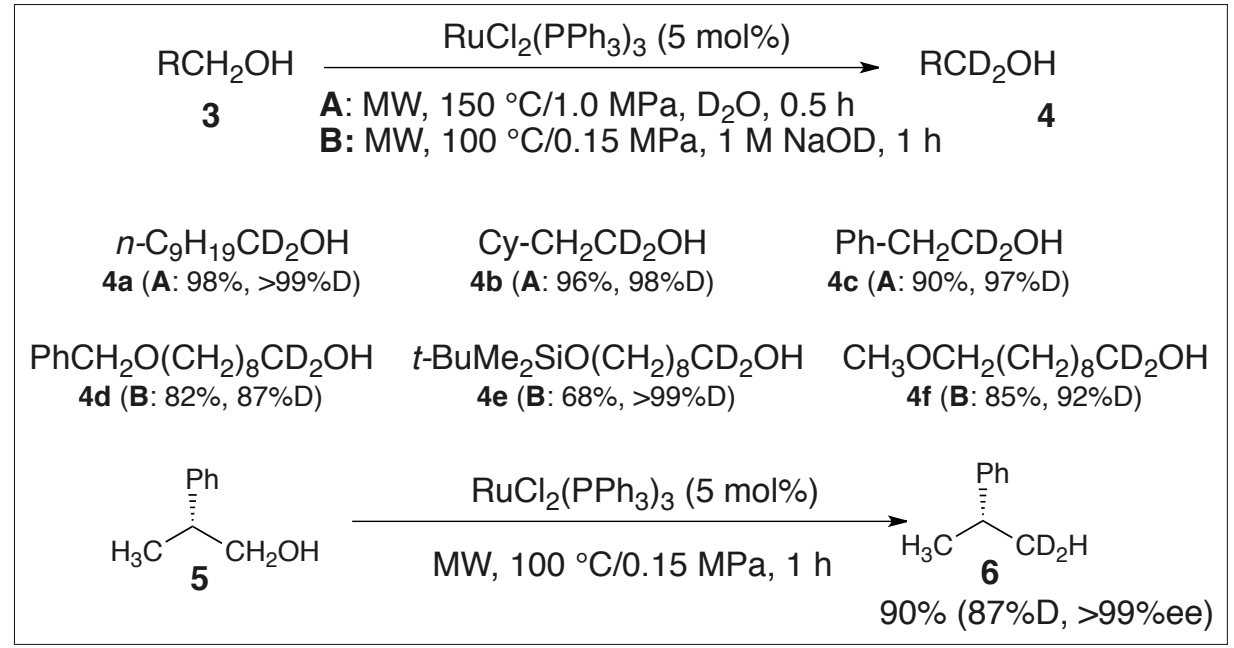

Scheme 3. Ruthenium-catalyzed H/D exchange of primary alcohols at the $\alpha$-position.

Scheme 4.

Ruthenium-catalyzed $\mathrm{H} / \mathrm{D}$ exchange of primary and secondary amines at the $\alpha$-position.

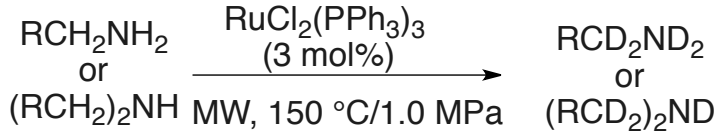

$$
\begin{aligned}
& 7 \quad \mathrm{D}_{2} \mathrm{O}, 0.5 \mathrm{~h} \quad 8 \\
& n-\mathrm{C}_{7} \mathrm{H}_{15} \mathrm{CD}_{2} \mathrm{~N}(\mathrm{D})_{2} \quad\left(n-\mathrm{C}_{5} \mathrm{H}_{11} \mathrm{CD}_{2}\right)_{2} \mathrm{~N}(\mathrm{D}) \\
& \text { 8a }(79 \%, 79 \% \mathrm{D} \text { at } \alpha) \quad \mathbf{8 b}(85 \%, 92 \% \mathrm{D} \text { at } \alpha)
\end{aligned}
$$

Scheme 5.

Ruthenium-catalyzed $\mathrm{H} / \mathrm{D}$ exchange of cyclohexene in $\mathrm{D}_{2} \mathrm{O}$.

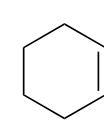

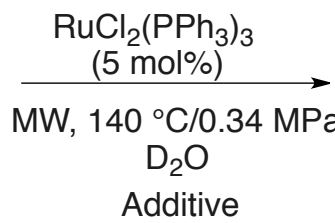

Additive

$\mathrm{MeOH}(20 \mathrm{~mol} \%) \quad 1 \mathrm{~h}$ $\mathrm{EtOH}(20 \mathrm{~mol} \%) \quad 1 \mathrm{~h}$ SDS (10 mol\%) $1 \mathrm{~h}$ SDS (10 mol\%)

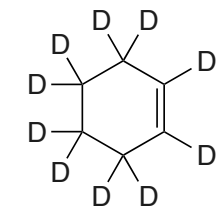

$0 \%$

$13 \%$

$97 \%$

\section{Palladium- and Platinum- catalyzed H/D Exchange on an $\mathrm{sp}^{3}$ Carbon under Hydrothermal Conditions}

$\mathrm{D}_{2} \mathrm{O}$ in the presence of $\mathrm{Pd} / \mathrm{C}$ resulted in the formation of fully deuterated products. As shown in Table 1, cyclic alkenes, alkanes, alkanones, and biphenyl were efficiently converted into the corresponding, fully deuterated products (entries 1-9). A linear hydrocarbon, $n$-pentadecane, was not deuterated completely because the $\mathrm{H}$-atoms on the terminal methyl groups remained (entry 10). ${ }^{[18]}$

The H/D exchange reaction on an $\mathrm{sp}^{3}$ carbon should proceed via a CMD mechanism $^{[19]}$ in the presence of $[\mathrm{Pd}-\mathrm{D}]^{+} \mathrm{OD}^{-}$. This cationic palladium species might form on the metal surface. Although the enthalpy change associated with the complete dissociation of water (to form metal oxide and hydride species) was reported to be large $(58 \mathrm{~kJ} / \mathrm{mol})$, the partial dissociation was estimated to be slightly exothermic $(-5 \mathrm{~kJ} / \mathrm{mol}){ }^{[20]}$ On the surface of palladium under hydrothermal conditions, the partial dissociation was not unreasonable. The palladium hydride was eluted during the partial dissociation stage as an active cationic species that accompanied the hydroxide ion partner (Fig. 2).

As shown in Scheme 6, treatment of 1-octene with catalytic amounts of $\mathrm{Pd} / \mathrm{C}$ (10 wt $\%, 10 \mathrm{~mol} \% \mathrm{Pd}$ ) in hydrothermal $\mathrm{H}_{2} \mathrm{O}\left(250{ }^{\circ} \mathrm{C} / 4 \mathrm{MPa}\right)$ for $2 \mathrm{~h}$ completely isomerized 1-octene into a mixture of internal alkenes without the formation of the hydrogenated product, octane. This result suggested that the eluted $\mathrm{Pd}-\mathrm{H}$ species had assisted with the alkene migration. At the same time, the absence of alkane in the product mixture suggested that complete dissociation did not occur.

During the alkene H/D exchange, it was not clear whether the deuteration of alkenes proceeded via the palladation of alkene at the allylic position or via the hydrometalation/elimination of palladium hydride to form the olefinic bond. The complete deuteration of saturated cyclic alkanes, as indicated in Table 1, strongly suggested that direct $\mathrm{C}-\mathrm{H}$ bond activation was largely involved in this case. Under hydrothermal $\mathrm{D}_{2} \mathrm{O}$, the eluted cationic palladium [Pd$\mathrm{D}^{+} \mathrm{OD}^{-}$could activate the $\mathrm{C}-\mathrm{H}$ bond on an $\mathrm{sp}^{3}$ carbon via the CMD mechanism. The reductive elimination formed a $\mathrm{C}-\mathrm{D}$ bond and $\operatorname{Pd}(0)$. It was then reabsorbed onto the Pd metal surface (Fig. 3). [21]

The metal-catalyzed H/D exchange of butylbenzene in hydrothermal $\mathrm{D}_{2} \mathrm{O}$ revealed a site selectivity that depended on the catalyst (Table 2). Although Pd black displayed selective deuteration on the butyl group, $\mathrm{PtO}$, promoted deuteration on the benzene ring. In fact, $\mathrm{PtO}_{2}$ was shown 
Table 1. H/D Exchange of hydrocarbons by the $P d / C$ catalyst under hydrothermal $D_{20}$.

\begin{tabular}{|c|c|}
\hline \multirow{2}{*}{ Substrate $\left(\mathrm{C}_{m} \mathrm{H}_{n}\right)$} & $10 \mathrm{wt} \% \mathrm{Pd} / \mathrm{C}(2 \mathrm{~mol} \%)$ \\
\hline & $\overrightarrow{\mathrm{D}_{2} \mathrm{O}, 250^{\circ} \mathrm{C}, 4 \mathrm{MPa}}$ Product $\left(\mathrm{C}_{m} \mathrm{D}_{n}\right)$ \\
\hline
\end{tabular}

\begin{tabular}{|l|l|c|c|c|}
\hline entry & Substrate & Time [h] & D [\%] & Yield [\%] \\
\hline 1 & Cyclooctene & 4 & $>95$ & 80 \\
\hline 2 & Cyclododecene & 4 & $>95$ & 84 \\
\hline 3 & Cyclododecane & 6 & $>95$ & 84 \\
\hline 4 & Cyclopentadecane & 4 & $>95$ & 99 \\
\hline 5 & Cyclooctanone & 10 & $>95$ & 86 \\
\hline 6 & Cyclodecanone & 12 & $>95$ & 83 \\
\hline 7 & Cyclododecanone & 4 & $>95$ & 87 \\
\hline 8 & Cyclopentadecanone & 10 & $>95$ & 99 \\
\hline 9 & Biphenyl & 14 & $>95$ & 88 \\
\hline 10 & $n$-Pentadecane & 16 & 76 & 98 \\
\hline
\end{tabular}

aSubstrate (5.0 mmol), Pd/C (10 wt\%, $100 \mathrm{mg}, 2$ mol\% Pd), $\mathrm{D}_{2} \mathrm{O}(20.0 \mathrm{~g})$. ${ }^{\text {ll }}$ lsolated Yields.

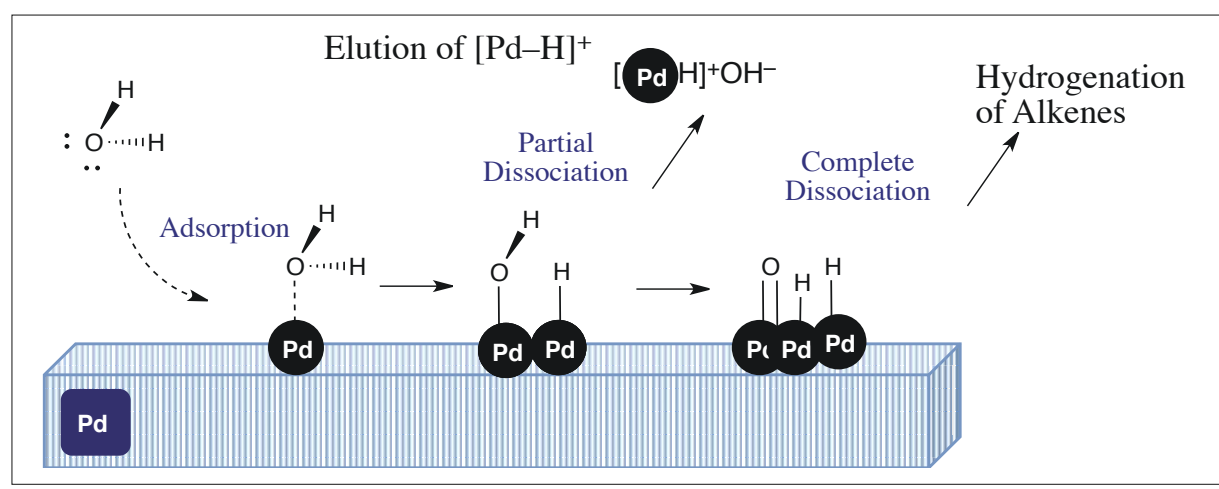

Fig. 2. Assumed formation of palladium(II) cationic species on the Pd metal surface under hydrothermal $\mathrm{H}_{2} \mathrm{O}$.

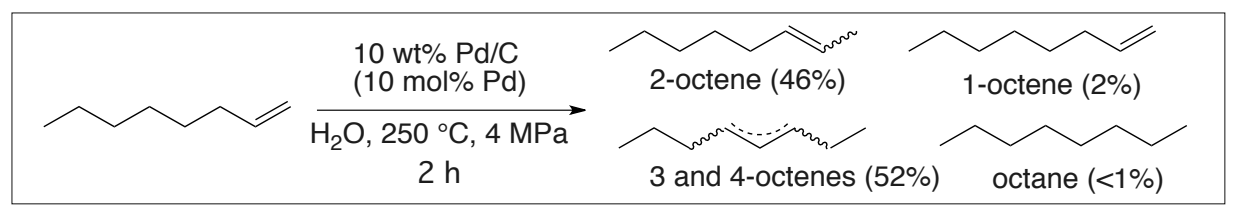

Scheme 6. Treatment of 1-octene with catalytic amounts of Pd in hydrothermal $\mathrm{H}_{2} \mathrm{O}$.

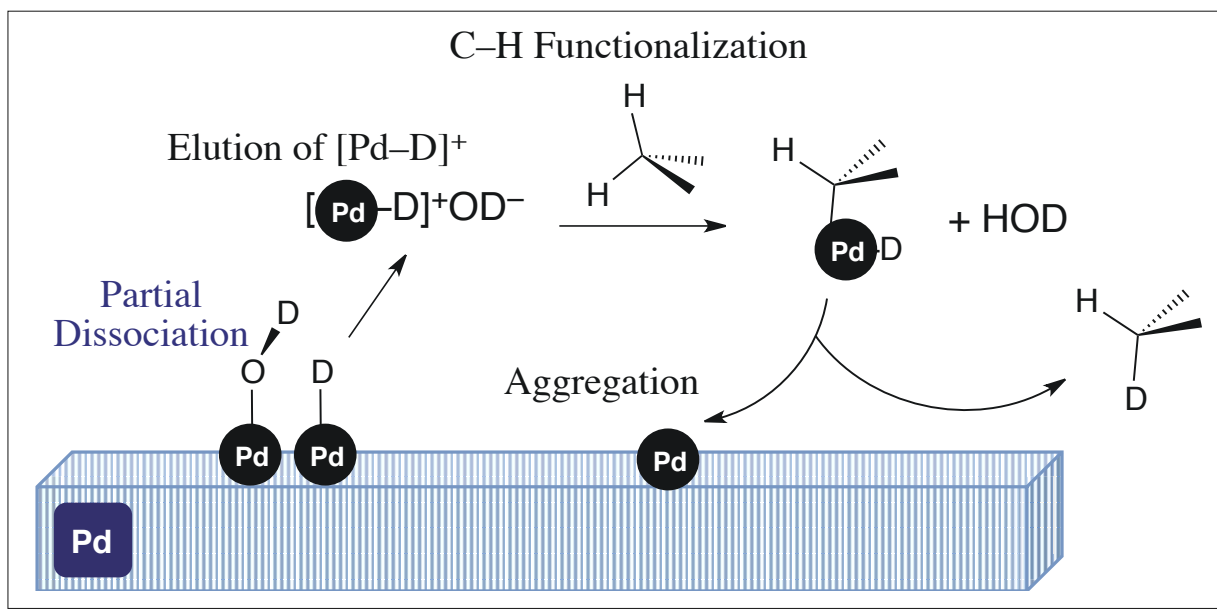

Fig. 3. Plausible mechanism for the $\mathrm{Pd}$-catalyzed $\mathrm{H} / \mathrm{D}$ exchange on an $\mathrm{sp}^{3}$ carbon under hydrothermal $\mathrm{D}_{2} \mathrm{O}$. to be an efficient catalyst for several aromatic rings, as shown in Scheme 7.[22] $\mathrm{H} / \mathrm{D}$ exchange on the aromatic ring may proceed via an electrophilic substitution mechanism. ${ }^{[19]}$

This H/D exchange protocol can be applied to arylsilanol. [23] As shown in Scheme 8, triphenylsilanol (9) was treated with a catalytic amount of $\mathrm{PtO}_{2}$ under hydrothermal $\mathrm{D}_{2} \mathrm{O}$. The exchange at the ortho-position did not reach completion due to steric hindrance. The obtained deuterated triphenylsilanol (10) was used as a coupling partner ${ }^{[24]}$ with iodobenzene to give the halfdeuterated biphenyl $\mathbf{1 1}$ quantitatively.

The metal-catalyzed H/D exchange protocol could be applied to an insoluble solid substrate. We attempted to deuterate a polymer, as some polydeuterated polymers are expected to act as novel optical materials. ${ }^{[25]}$ The transparency of polydeuterated polymers to infrared beams would be useful for preparing efficient optical waveguides. ${ }^{[25]}$ As shown in Scheme 9, polystyrene samples with various molecular weights (the commercially available butyllithium-initiated standard polystyrenes) were examined in a $\mathrm{PtO}_{2}$-catalyzed H/D exchange reaction under hydrothermal $\mathrm{D}_{2} \mathrm{O} \cdot{ }^{[26]}$ The H/D exchange efficiency decreased in the higher molecular weight samples, but even in the Mw 280000 sample, $38 \%$ of $\mathrm{H}$-atoms in the benzene ring were exchanged with D-atoms.

\section{Palladium-catalyzed H/D Exchange Accompanying Decarboxylation under Hydrothermal Conditions}

Except for some activated carboxylic acids, such as aryl carboxylic acid, the decarboxylation of free carboxylic acids is often difficult to perform. The high-temperature gas phase reaction is reported to be effective when conducted under $\mathrm{H}_{2}$ gas in the presence of a $\mathrm{Pd}$ or $\mathrm{Ni}$ catalyst. [27] We treated a carboxylic acid $\mathbf{1 2}$ with hydrothermal $\mathrm{D}_{2} \mathrm{O}\left(250{ }^{\circ} \mathrm{C} / 4 \mathrm{MPa}\right)$ for 12 $\mathrm{h}$ and obtained the completely deuterated decarboxylated product $\mathbf{1 3}$ in $89 \%$ yield (Scheme 10).[28] The metal-catalyzed H/D exchange reaction under hydrothermal $\mathrm{D}_{2} \mathrm{O}$ did not readily yield the trideuteriomethyl group (-CD $)_{3}$; however, the decarboxylation procedure was shown to be appropriate for preparing a compound with a $\mathrm{CD}_{3}$ group. The lactone 14 was converted into the perfectly deuterated compound $\mathbf{1 5}$ via decarboxylation.

\section{Conclusion}

A very simple protocol involving heating organic compounds with $\mathrm{D}_{2} \mathrm{O}$ in a 
Table 2. Various metal-catalyzed $\mathrm{H} / \mathrm{D}$ exchange reactions on butylbenzene under hydrothermal $\mathrm{D}_{2} \mathrm{O} \cdot{ }^{\mathrm{ab}}$

- $\mathrm{CH}_{2}-\mathrm{CH}_{2}-\mathrm{CH}_{2}-\mathrm{CH}_{3} \frac{10 \mathrm{wt} \% \mathrm{Pd} / \mathrm{C}}{(2 \mathrm{~mol} \% \mathrm{Pd})} \underset{\mathrm{D}_{2} \mathrm{O}, 250^{\circ} \mathrm{C}, 4 \mathrm{MPa}}{\longrightarrow}$

\begin{tabular}{|l|c|c|c|c|c|c|c|}
\hline entry & Catalyst & Time / h & \multicolumn{5}{|c|}{ Content Ratio of D (\%) } \\
\hline & & & $\mathbf{C}^{\mathbf{A r}}$ & $\mathbf{C}^{\mathbf{1}}$ & $\mathbf{C}^{\mathbf{2}}$ & $\mathbf{C}^{\mathbf{3}}$ & $\mathbf{C}^{\mathbf{4}}$ \\
\hline 1 & $\mathrm{Pd} / \mathrm{C}$ & 2 & 20 & 67 & 42 & 49 & 43 \\
\hline 2 & $\mathrm{PdO}$ & 2 & 2 & 61 & 38 & 50 & 42 \\
\hline 3 & $\mathrm{Pd}$ black & 2 & $<2$ & 32 & 14 & 24 & 16 \\
\hline 4 & $\mathrm{PtO}_{2}$ & 2 & 28 & 42 & 26 & 32 & 30 \\
\hline 5 & $\mathrm{PtO}_{2}$ & 4 & 65 & 58 & 49 & 48 & 40 \\
\hline 6 & $\mathrm{PtO}_{2}$ & 6 & 81 & 75 & 59 & 65 & 56 \\
\hline 7 & $\mathrm{PtO}_{2}$ & 14 & 96 & 95 & 94 & 95 & 83 \\
\hline
\end{tabular}

aSubstrate $(2.0 \mathrm{mmol})$, catalyst $\left(2 \mathrm{~mol} \%\right.$ metal), $\mathrm{D}_{2} \mathrm{O}(20.0 \mathrm{~g}) .{ }^{\mathrm{b}}$ The ratios were determined by ${ }^{1} \mathrm{H}$ NMR and ${ }^{2} \mathrm{H}$ NMR.

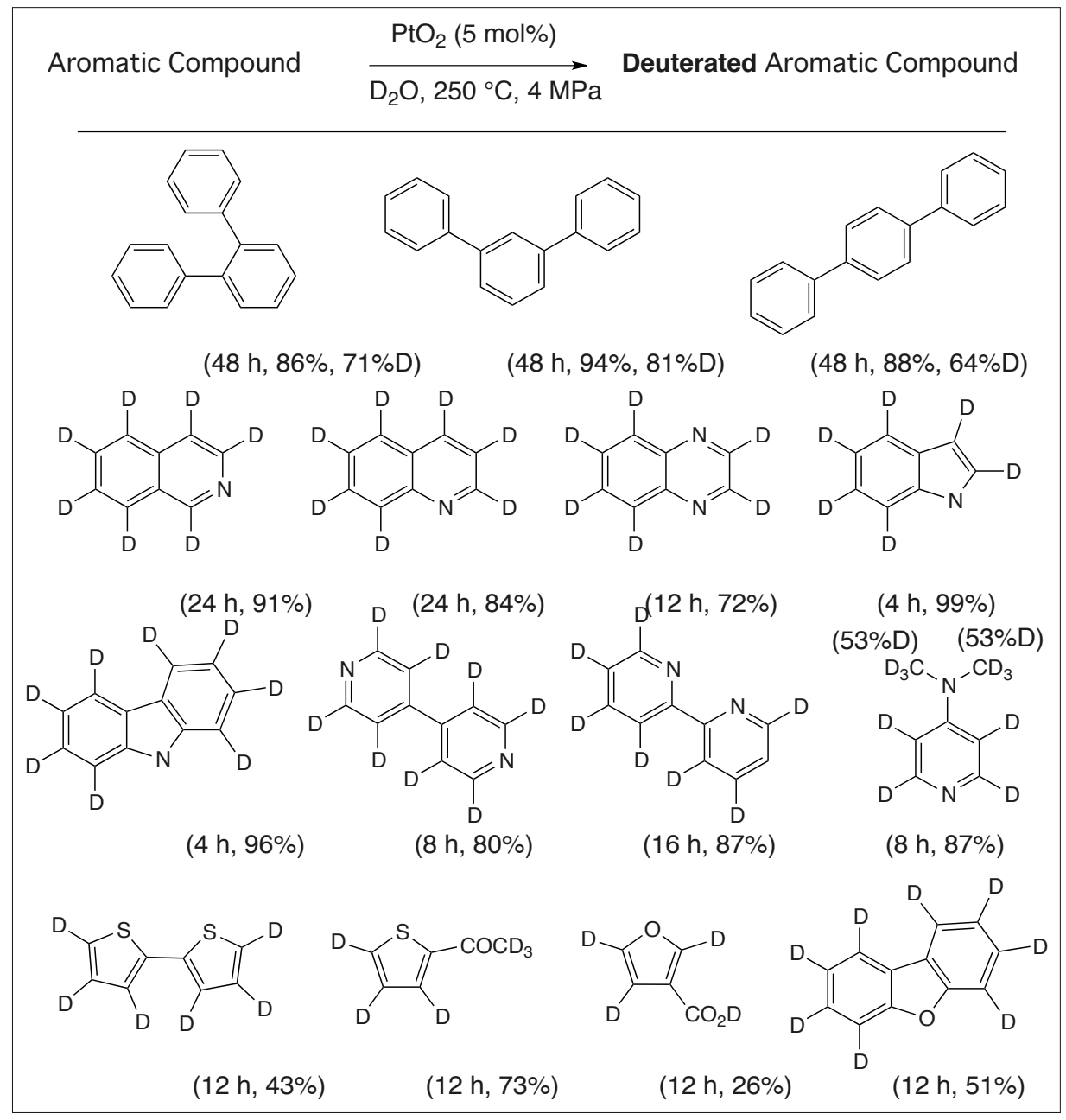

Scheme 7. $\mathrm{PtO}_{2}$-catalyzed $\mathrm{H} / \mathrm{D}$ exchange reaction of aromatic compounds under hydrothermal $\mathrm{D}_{2} \mathrm{O}$.

sealed container in the presence of metal catalyst gave us a powerful method of preparing D-labeled compounds. This method supplied fully deuterated organic molecules, which are potentially useful as new drugs or new functional materials.
The partially D-labeled compounds are clearly similar to the corresponding nondeuterated compounds, although the corresponding fully D-labeled molecules are completely new molecules. The properties of these compounds must be studied in an effort to create novel drugs and materials.

\section{Acknowledgements}

This work was supported by the JSPS KAKENHI Grant Numbers 15H05845 and 17K19120. Financial support from Fujifulm Corporation is also acknowledged.

Received: July 27, 2018

[1] a) Y. Y. Loh, K. Nagao, A. J. Hoover, D. Hesk, N. R. Rivera, S. L. Cokketti, I. W. Davies, D. W. C. MacMillan, Science 2017, 358, 1182; b) J. Atzrodt, V. Derdau, T. Fey, J. Zimmermann, Angew. Chem. Int. Ed. 2007, 46, 7744; c) X. Liang, S. Duttwyler, Asian J. Org. Chem. 2017, 6, 1063; d) S. Matsubara, K. Oshima, J. Org. Synth. Soc. Jpn 2005, 63, 154; e) Y. Sawayama, K. Park, T. Yamada, H. Sajiki, Chem. Pharm. Bull. 2018, 66, 21; f) V. Soulard, G. Villa, D. P. Vollmar, P. Renaud, J. Am. Chem. Soc. 2018, 140, 155.

[2] a) P. H. Allen, M. J. Hickey, L. P. Kingston, D. J. Wilkinson, J. Labelled Compd. Radiopharm. 2010, 53, 731; b) E. M. Isin, C. S. Elmore, G. N. Nilsson, R. A. Thompson, L. Weidolf, Chem. Res. Toxicol. 2012, 25, 532; c) J. Atzrodt, V. Derdau, W. J. Kerr, M. Reid, Angew. Chem. Int. Ed. 2018, 57, 1758.

[3] a) M. Miyashita, M. Sasaki, I. Hattori, M Sakai, K. Tanino, Science 2004, 305, 495; b) J. K. C. Abbott, L. Li, Z.-L. Xue, J. Am. Chem. Soc. 2009, 131, 8246.

[4] a) T. G. Gant, J. Med. Chem. 2014, 57, 3595; b) M. Dean, V. W. Sung, Drug Des. Devel. Ther. 2018, 12, 313; c) L. Citrome, Int. J. Clin. Pract. 2017, 71, e13030.

[5] a) O. Ostroverkhova, Chem. Rev. 2016, 116, 13279; b) M. Shao, J. Keum, J. H. Chen, Y. J. He, W. Chen, J. F. Browning, J. Jakowski, B. G. Sumpter, I. N. Ivanov, Y. Z. Ma, C. M. Rouleau, S. C. Smith, D. B. Geohegan, K. L. Hong, K. Xiao, Nature Commun. 2014, 5, 4180.

[6] a) J. H. Ardenkjaer-Larsen, J. Magn. Reson. 2016, 264, 3; b) M. J. Moure, Y. Zhuo, G. J. Boons, J. H. Prestegard, Chem. Commun. 2017, $53,12375$.

[7] D. Bröll, C. Kaul, A. Krämer. P. Krammer, T. Richter, M. Jung, H. Vogel, P. Zehner, Angew. Chem. Int. Ed. 1999, 38, 2998.

[8] a) 'Microwaves in Organic Synthesis', Eds A De La Hoz, A. Loupy, Wiley-VCH, Weinheim, 3rd edn, 2013; b) C. O. Kappe, Chem. Soc. Rev. 2013, 42, 4977. c) S. Matsubara, in 'Handbook of C-H Transformations', vol 2, Ed. G. Dyker, Wiley-VCH, Weinheim, 2005, p 438.

[9] M. Schlosser, Chem. Ber. 1964, 97, 3219.

[10] M. Yamamoto, K. Oshima, S. Matsubara, Chem. Lett. 2004, 33, 846.

[11] N. Asakura, T. Hirokane, H. Yamada, Tetrahedron Lett. 2011, 52, 534.

[12] M. Oliverio, P. Costanzo, M. Nardi, C. Calandruccio, R. Salerno, A. Procopio, Beilstein J. Org. Chem. 2016, 12, 2222.

[13] V. Sridharan, J. C. Menendez, Chem. Rev. 2010 110,3805 .

[14] H. Tomioka, K. Takai, K. Oshima, H. Nozaki, Tetrahedron Lett. 1981, 22, 1605.

[15] M. Takahashi, K. Oshima, S. Matsubara, Tetrahedron Lett. 2003, 44, 9201.

[16] M. Takahashi, K. Oshima, S. Matsubara, Chem. Lett. 2005, 34, 192. 
Scheme 8. $\mathrm{PtO}_{2}$ catalyzed $\mathrm{H} / \mathrm{D}$ exchange reaction of arylsilanol under hydrothermal $\mathrm{D}_{2} \mathrm{O}$.

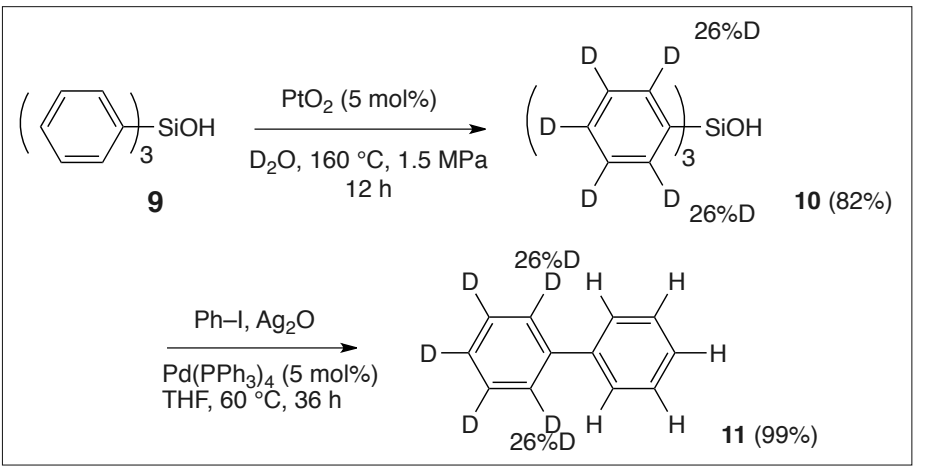

Scheme 9. $\mathrm{PtO}_{2}-$ catalyzed H/D exchange reaction of polystyrenes under hydrothermal $\mathrm{D}_{2} \mathrm{O}$.

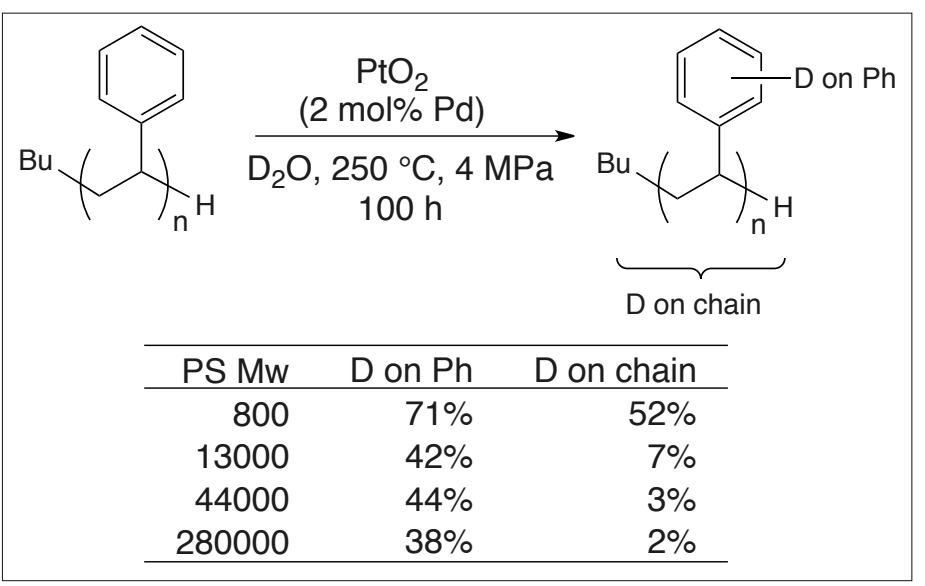

Scheme 10. Pdcatalyzed decarboxylative $\mathrm{H} / \mathrm{D}$ exchange reaction under hydrothermal $\mathrm{D}_{2} \mathrm{O}$.
[17] K. Ishibashi, S. Matsubara, Chem. Lett. 2007, 36,724 .

[18] S. Matsubara, Y. Yokota, K. Oshima, Chem. Lett. 2004, 33, 294.

[19] L. Ackermann, Chem. Rev. 2011, 111, 1315.

[20] P. A. Thiel, T. E. Madey, Sur. Sci. Rep. 1987, 7, 211.

[21] S. Matsubara, K. Asano, Y. Kajita, M. Yamamoto, Synthesis 2007, 2055.

[22] M. Yamamoto, K. Oshima, S. Matsubara, Heterocycles 2006, 67, 353.

[23] M. Yamamoto, K. Oshima, S. Matsubara, Org. Lett. 2004, 6, 5015 .

[24] Y. Hatanaka, T. Hiyama, Synlett 1991, 845.

[25] a) T. Kurihara, N. Ooba, S. Toyoda, T. Maruno, Oyobuturi 2002, 71, 1508; b) T. Kaino, K. Jinguji, S. Nara, Appl. Phys. Lett. 1983, 42, 567.

[26] M. Yamamoto, Y. Yokota, K. Oshima, S Matsubara, Chem. Commun. 2004, 1714.

[27] W. F. Maier, W. Roth, I. Thies, P. R. Schleyer, Chem. Ber. 1982, 115, 808

[28] S. Matsubara, Y. Yokota, K. Oshima, Org. Lett. 2004, 6, 2971. 